\title{
Biomechanical Evaluation of Hemiarthroplasty in the First Proximal Phalanx. A Finite Element Study
}

\author{
M. A. Madrid-Pérez', R. Becerro de Bengoa-Vallejo², J. Bayod-López³ \\ 'Escuela de Ingeniería y Arquitectura, Universidad de Zaragoza. Facultad de Ingeniería, Universidad Autónoma de Chihuahua \\ Escuela de Enfermería, Fisioterapia y Podología, Universidad Complutense de Madrid \\ ${ }^{3}$ Escuela de Ingeniería y Arquitectura, Universidad de Zaragoza
}

\section{ABSTRACT}

Hallux rigidus produces a decrease in the dorsiflexion of the first metatarsophalangeal joint and is usually associated with the appearance of osteophytes. Hemiarthroplasty in the first proximal phalanx is a recommended surgical procedure in patients with advanced grade of hallux rigidus. Finite element analysis allows us to understand the biomechanical behavior of the foot. The objective of this work is to evaluate the biomechanical effects of an hemi implant placed in first proximal phalanx. Two models of finite elements are going to be compared, one free of pathologies and the other with a hemiarthroplasty in the first ray of the foot. We detected after inserting the prosthesis in the model that passive windlass mechanism is lost, and the lesser toes become overloaded, which leads to a loss of efficiency in gait as well as being able to cause postsurgical medical complications.

KEYwORDS: Hemiarthroplasty; Hallux Rigidus; Finite Element Analysis; First Metatarsophalangeal Joint

\section{Corresponding author}

TO: Mario Alberto Madrid Pérez

INSTITUTION: Facultad de Ingeniería, Universidad

Autónoma de Chihuahua

ADDRESS: Circuito Número IS/N, Nuevo Campus

Universitario II, C. P. 31125, Chihuahua, Chihuahua,

México

E-MAIL: 715181@unizar.es; mmadrid@uach.mx

\section{Received:}

22 September 2020

Accepted:

11 February 2021 


\section{INTRODUCTION}

Hallux Rigidus (HR) is characterized by permanent pain with joint crunches when performing the mobilization of the great toe. The pain is increased when walking and standing up. HR is usually associated with a decrease in joint function, as well as the appearance of a lump or excrescence in the metatarsophalangeal dorsal region of the First Ray of the Foot (FRotF) ${ }^{[1]}$. This pathology is usually associated with a limitation of the movement of the FRotF, especially in dorsiflexion, medically called osteoarthritis of the metatarsophalangeal joint of the great toe ${ }^{[2]}$. The mobility arc of the First Metatarsophalangeal Joint (FMJ) is 110 degrees, with a plantar flexion of 35 degrees and dorsal flexion of 75 degrees. In HR the range of mobility decreases, with a decrease in dorsiflexion ${ }^{[3]}$.

To date, there is no technique that can be applied to all the different grades of HR. The treatments against HR have had considerable advances in recent years. The destructive surgical techniques include arthrodesis, arthroplasty, and cheilectomy, while the nondestructive surgical techniques include many kinds of osteotomies ${ }^{[2]}$. Arthroplasty is a surgical procedure where the skeletal muscle's surface of an articular joint is remodeled, replaced, or realigned. There are three different types of arthroplasty: The interposition arthroplasty where some tissue is interposed, such as a muscle or a tendon to keep some distance between the bones. The resection arthroplasty where the resected bone is removed and the implant arthroplasty where the bony surfaces of proximal phalanx and/or head of first metatarsal bone are removed and replaced by an implant ${ }^{[4]}$. The surgical treatment and the type of technique to be used depend on the stage in which it is found and the morphological type of the forefoot. However, all methods should be aimed at supplying the function of the first phalanx during the moment of toe-off in walking ${ }^{[1]}$. As mentioned above, there are many treatments for the described pathology, but it is not yet clear which treatments are better than others.
The present work focuses on implant arthroplasty. This surgical technique remains controversial. Implant arthroplasty has the advantage of being a technique that can alleviate pain and restore the mobility of the FMJ but also has the disadvantage of being a destructive procedure, which is why it is considered one of the last options ${ }^{[5]}$. This project presents a biomechanical evaluation of an implant arthroplasty using the AnaToemics ${ }^{\circledR}$ Phalangeal Prosthesis by Arthrex. The implant researched in this paper is recommended to be used in patients with HR in grade III or IV and with patients with moderate hallux valgus (HV) ${ }^{[5][6]}$.

To date, no scientific articles have been presented that display a biomechanical evaluation for this type of hemi-implant. Finite element models are a good technique to understand these effects ${ }^{[4]}{ }^{[7][8][9]}$ and are more economical and easier to carry out than experimental ones (either in vivo or on cadavers). Reference ${ }^{[4]}$ discusses a foot model after an arthroplasty has been developed using two types of implants, Swanson and Tornier joint implants. Reference ${ }^{[7]}$ makes an analysis of the foot varying the size of the first proximal phalanx. Reference ${ }^{[8]}$ researches the load distribution in first metatarsal bone and reference ${ }^{[10]}$ makes an analysis of the foot when hemiarthroplasty in the first metatarsal bone has been developed using the hemi-implant HemiCAP ${ }^{\circledR}$ Toe DF by Arthrosurface. The objective of this work is to understand the biomechanical effect generated by a hemiarthroplasty of the FRotF using the hemi-implant AnaToemics ${ }^{\circledR}$ Phalangeal by Arthrex. To do this, displacements and tensions will be compared in two computational models, one healthy and the other one with a hemiarthroplasty.

The hemiarthroplasty process consists in aligning the first ray of the foot, if there are osteophytes they are removed, first proximal phalanx is resected, the implant is inserted and some muscles and tendons are disconnected ${ }^{[10]}$. By making this process in a finite element model of the foot with the aim to understand the impact 
of the first proximal phalanx hemiarthroplasty on the gait biomechanics. The stresses and displacements of both healthy and hemiarthroplasty models are analysed during toe-off in order to evaluate the effects of the implant on the gait biomechanics, specifically on the first ray of the foot The healthy model induces stresses and displacements that must correspond with the biomechanics of the foot in the literature of the toe-off phase and the hemiarthroplasty model induces displacements and stresses that let us know how the implant works and how the biomechanics of the human gait changes with the process of hemiarthroplasty, especially to know if there are or there are not any consequences in the biomechanics of the first ray of the foot.

\section{MATERIALS AND METHODS}

\section{Healthy model}

The healthy model presented was developed by the University of Zaragoza (Spain). 93 computed tomography scans were necessary for the foot scan. The creation of volumes was done considering cortical and trabecular bone. The maximum and minimum size element was of $3 \mathrm{~mm}$ and $0.31 \mathrm{~mm}$ respectively with an average of $1.78 \mathrm{~mm}$ solving in that way the model convergence problem. The foot is modelled during toe-off since at this phase the maximum stresses occur in the FRotF ${ }^{[7]}$. For bones and cartilage, we use tetrahedral elements due is a good type of element to mesh complicated geometries, for muscles and tendons we use beam elements because they experiment directly a pretension force due to the position of toe-off and for thin ligaments, plantar ligaments, and plantar fascia we use bar elements due they only suffer small displacements in their extreme nodes when the model is loaded ${ }^{[4]}[7][9][15]$ [16] [17] [18] [24]. Fig. 1 shows the elements that this model contains. All bones, cartilage, and soft tissues were considered as homogeneous, isotropic, and linearly deformable bodies. This model (without an implant) contains 150,594 nodes and 802,294 elements. More details about this model can be found in ${ }^{[4]}[9]$.

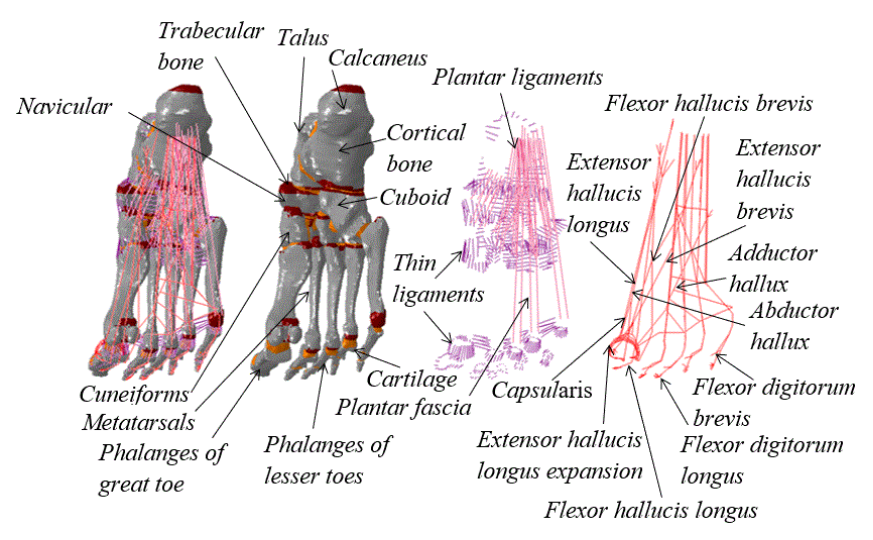

FIGURE 1. Elements of the model without an implant.

\section{Hemiarthroplasty model}

The second model presented in this article contains the insertion of the hemi-implant AnaToemics ${ }^{\circledR}$ Phalangeal Prosthesis by Arthrex in the proximal phalanx of the great toe. To obtain the volume of the implant, we used a 3D scanner provided by the University of Zaragoza. According to the surgical procedure, the first proximal phalanx is resected to later introduce the implant. To make this cut in the proximal phalanx, Mimics 10.0 was used after the prosthesis was placed with the help of Softimage 2015 and exporting the entire model in the .STL format. The mesh for hemiarthroplasty model was creating with ICEM CFD 17.2 of ANSYS having in the entire model a maximum and minimum element size of $3.8 \mathrm{~mm}$ and $0.18 \mathrm{~mm}$ respectively with an average of $1.13 \mathrm{~mm}$, in the implant the maximum and minimum size of element was $3 \mathrm{~mm}$ and $0.42 \mathrm{~mm}$ respectively with an average of $1 \mathrm{~mm}$ preserving in that way the geometry of the first ray after having developed the surgical procedure, in addition to solving the model convergence problem. When the maximum element size in the implant is $5 \mathrm{~mm}$, the minimum size is $0.7 \mathrm{~mm}$ and the average size is $1.7 \mathrm{~mm}$, there are no significant changes in the calculations of stresses and deformations in the implant. Hemiarthroplasty model has a more refined mesh than healthy model due to the surgical procedure. To maintain the geometry of the soft tissues MATLAB R2013b programming was used to insert 
muscles, tendons, and ligaments calculating the minimum distance of the nodes of healthy model with the nodes of hemiarthroplasty model.

For this model with implant, some muscles and tendons have been removed as well as some ligaments of the first metatarsophalangeal joint as part of the hemiarthroplasty process ${ }^{[10]}$. Fig. 2 shows the elements of the model with the implant and Fig. 3 shows the hemi implant and its mesh, it is worth to note that in the part of the implant (spikes) inserted in the trabecular bone of the first proximal phalanx, the stresses and deformations are small values, so the mesh size adequately solves the model convergence problem. Hemiarthroplasty model contains 1,836,607 elements and 329,159 nodes.

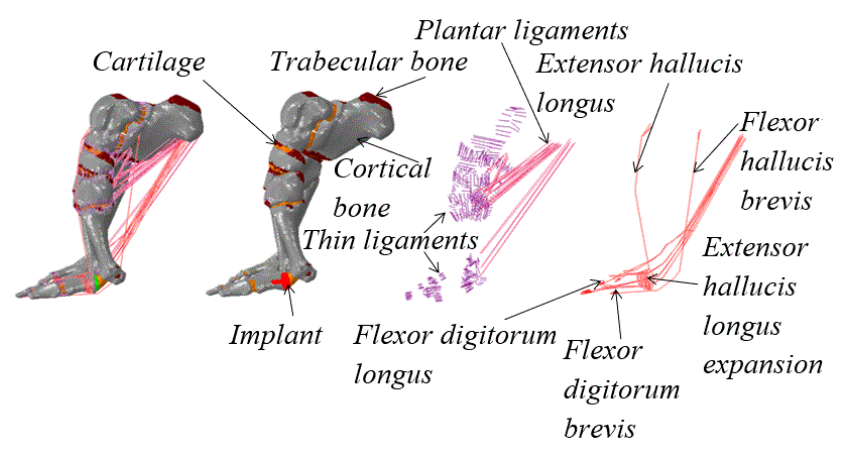

FIGURE 2. Elements of the model with the implant.

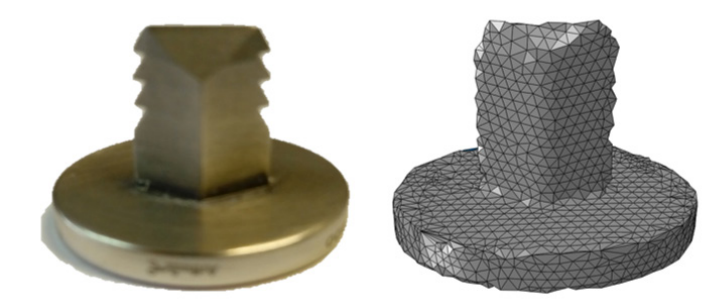

FIGURE 3. The implant and mesh from the implant.

\section{Mechanical properties and boundary conditions}

The mechanical properties, as well as boundary and load conditions that are used in the two models presented in this paper, are the same, so they will only be defined once ${ }^{[4]}{ }^{[7]}$. All elements were considered as homogeneous, isotropic, and linearly deformable elastic because there are only small displacements and small deformations. For cortical bone, trabecular bone, muscles, thin ligaments and plantar ligaments, a modulus of elasticity of 17000, 700, 450, 260 and $350 \mathrm{MPa}$ respectively has been used, all the elements mentioned above have a Poisson coefficient of 0.3. For cartilage a Young's modulus of $10 \mathrm{MPa}$ and a Poisson's ratio of 0.4 were used and for the cobalt-chrome hemi implant a Poisson's ratio of 0.29 and an elastic modulus of $210 \mathrm{GPa}$ have been used [11] [12] [13] [14].

Some authors divide the human gait cycle into three stages, while others define six or eight stages ${ }^{[15]}$. Regardless of the classification of the human gait that is taken, it is well-documented that the maximum efforts at the FRotF occur in the position of the toe-off [7].

The models presented are in the toe-off stage and correspond to a person weighing $60 \mathrm{~kg}$. The analysis was performed in the Abaqus 6.13-5 software. For the analysis, two steps were used. In the first step, a pretension force of $2 \%$ is added to the muscles as consequence of the toe-off phase. This pretension force has been obtained by measuring the elongation of the

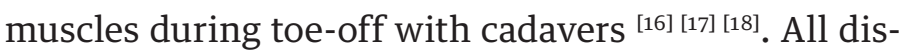
placements of some nodes on the attachment surface of the Achilles tendon are restricted. All degrees of freedom were constrained at the base of the first two proximal phalanges. Vertical translations and rotations in the distal phalanges of the lesser toes are restricted. In the second step, the pretension force is maintained, and the weight of the person is added, considering a force of $1805 \mathrm{~N}^{[15]}$. A contact pair frictionless was used between the outer surface of the tetrahedral elements with the muscles and tendons. The master surface is made up of triangular elements while the slave surface is made up of the nodes of the muscles and tendons. Fig. 4 shows how the body weight acts on the model; this load was applied in the area where the fibula and the tibia meet the talus. 
With the aim to understand how the implant functions when it is overloaded, we simulate the foot during toeoff loading 2 and 2.5 times the weight of the person.

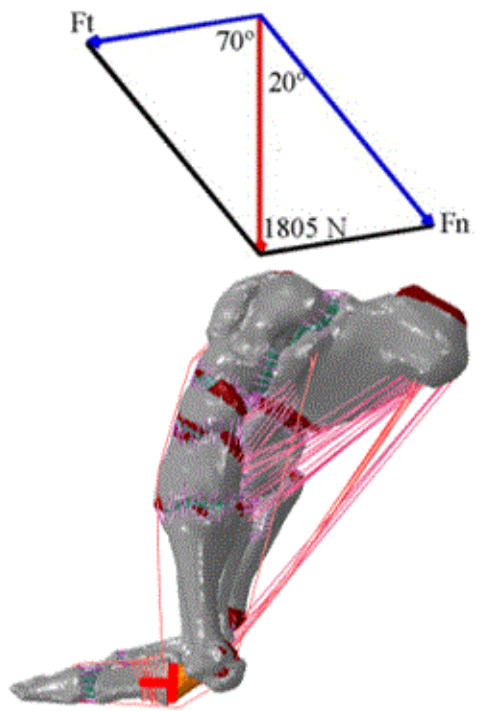

FIGURE 4. Loads due to the person's own weight.

\section{RESULTS AND DISCUSSION}

\section{Results for model without an implant}

In the healthy model the first distal phalanx acquires a movement in the sagittal plane. This movement is due to the force reaction that the ground exerts on the person and produces a forward impulse, giving directionality to the gait ${ }^{[19]}$. In Fig. 5, we can see this movement, which is commonly known as the passive windlass mechanism, and we can see too the principal stresses for the model. For the first distal phalanx, the maximum concentration of principal stresses occurs in the dorsal area, where the tendons of extensor hallucis longus muscle act. Concentrations of principal stresses at the support points appear for the second and third ray of the foot. The maximum displacement occurs in the phalanges of the fifth ray of the foot.

\section{Results for model with the implant}

For the second model presented in this article, concentrations of principal stresses appear in the second ray of the foot and calcaneus. For the FRotF, the great-

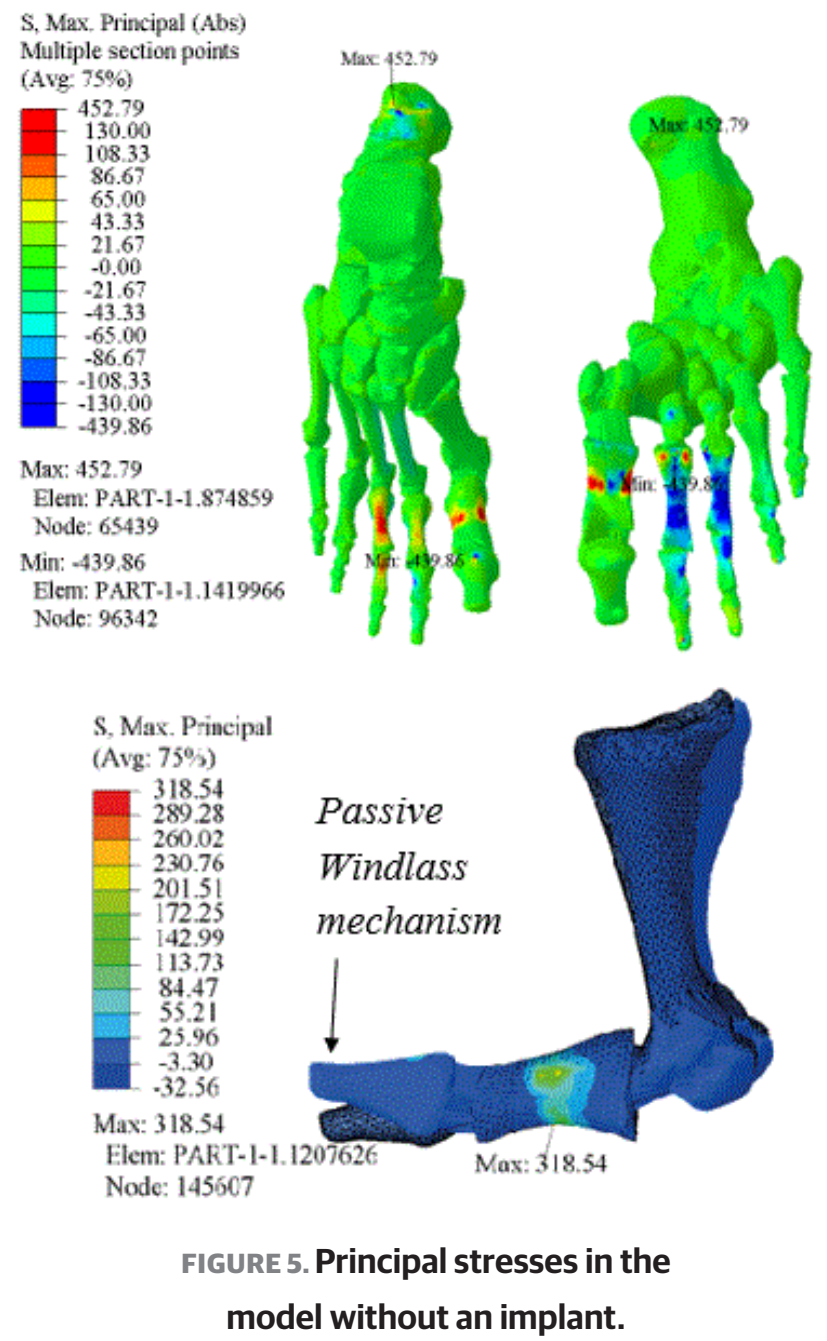

est concentration of principal stresses appears in the support points. For the second and third rays, the highest stress concentration occurs in the proximal phalanges. For the second and third rays of the foot, the greatest concentration of major stress occurs in the proximal plantar area of the proximal phalanges. The greatest displacement occurs in the third and fifth rays of the foot in the phalangeal area. The function of the passive windlass mechanism is lost. The stresses and displacements mentioned previously can be contemplated in Fig. 6. In upper part of Fig. 7 the displacements for the healthy model in the three loading conditions are shown. In the lower part, appear the displacements for the three loading conditions in the model with the implant. The units of the displacements are millimeters. 


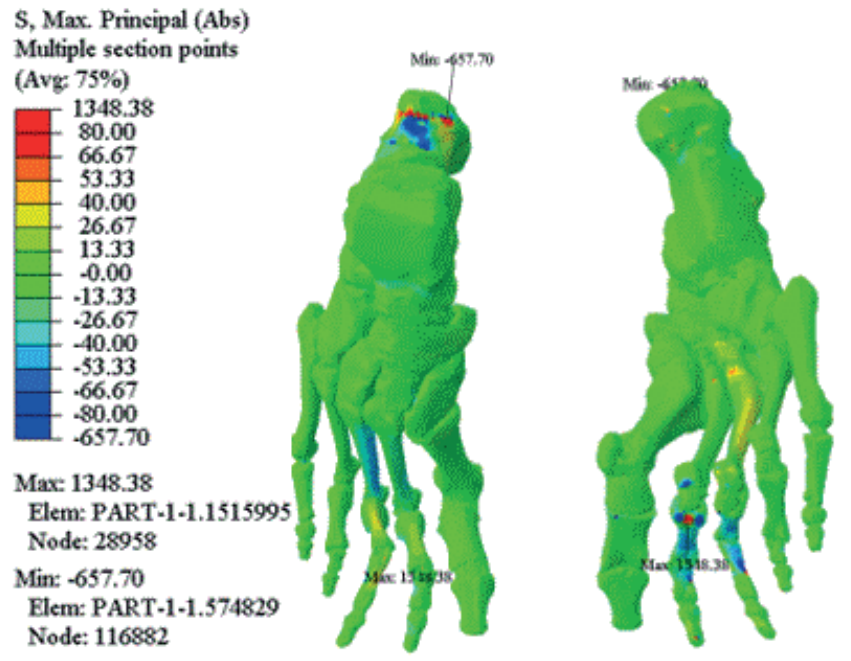

S, Max. Principal

(Avg: 75\%)

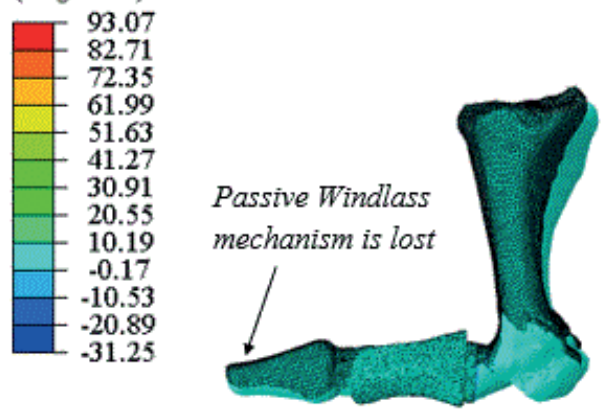

FIGURE 6. Principal stresses in the model with implant.

The maximum von Mises stress on the implant is 27 MPa (Fig. 8). The maximum principal stress registered in the implant is $29 \mathrm{MPa}$, and this occurs in the join of the oval part with the pilot pin. The highest absolute value of the minimum principal stress in the implant is $27 \mathrm{MPa}$ (compression stress), and it appears in the oval part. Table 1 presents a comparison of the maximum Von Mises stresses developed in the implant when loading condition is 1.0, 2.0 and 2.5 the body weight.

\section{Discussion}

Arthroplasty using the AnaToemics ${ }^{\circledR}$ Phalangeal Prosthesis by Arthrex is a recommended procedure for patients with HR grade 3 and 4 who have failed conservative treatment for at least 6 months. This proce-
TABLE 1. Comparison of maximum equivalent Von Mises stress in implant.

\begin{tabular}{cc}
\hline Loading condition & Von Mises Stress (MPa) \\
\hline 1.0 times the person's own weight & 27.47 \\
\hline 2.0 times the person's own weight & 61.60 \\
\hline 2.5 times the person's own weight & 78.63 \\
\hline
\end{tabular}

dure requires that the patient has a well-aligned and stable FMJ ${ }^{[5]}$. Despite the fact that the use of implants is becoming more and more common, no studies have been carried out using Finite Element Analysis to know the consequences that these types of implants produce in the foot ${ }^{[20]}$.
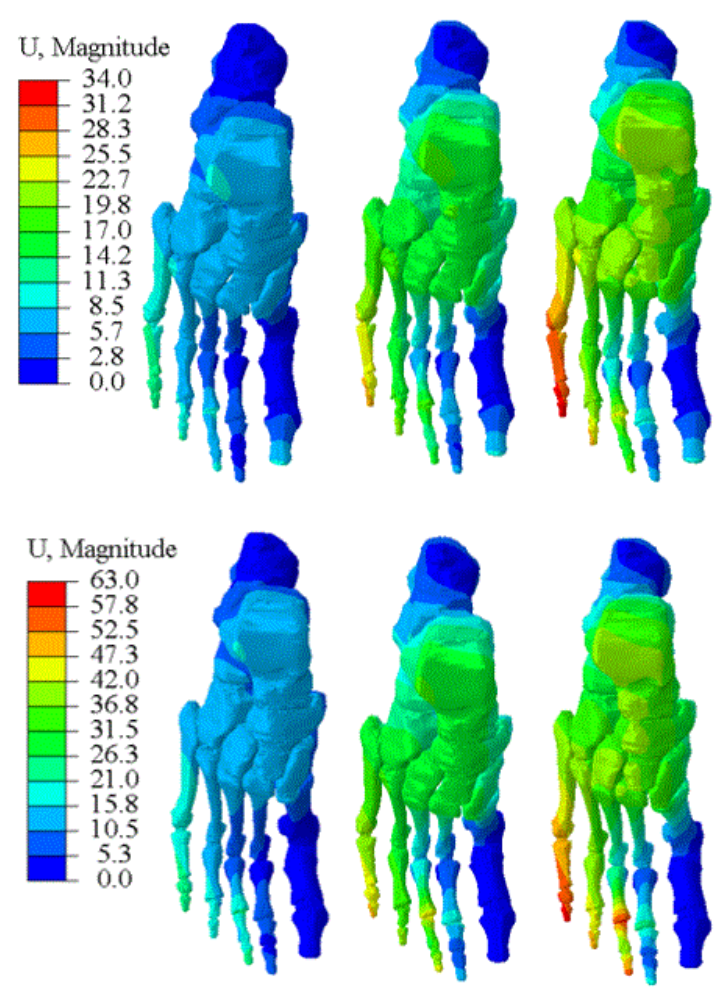

FIGURE 7. Displacements values for healthy model (upper part) and hemiarthroplasty model (lower part) for all load conditions.

Eric Eric Giza et al. ${ }^{[21]}$ report 22 Hemiarthroplasties in the First Proximal Phalanx (HitFPP) in 20 patients. Preoperative radiographs revealed 14 cases of grade 3 and 8 cases of grade $4 \mathrm{HR}$, according to the classifica- 


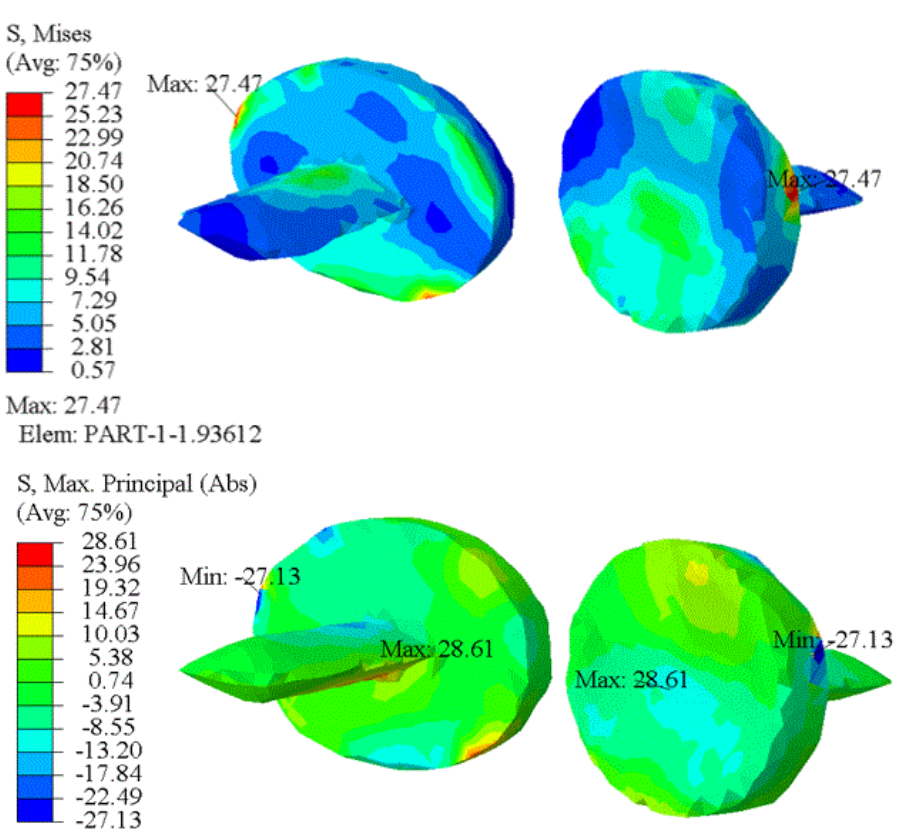

Max: 28.61

Elem: PART-1-1.1608541

\section{FIGURE 8. Von Mises stresses and absolute maximum principal stresses.}

tion of Coughlin and Shurnas. The average dorsiflexion of the FMJ improved from 41 with a Standard Deviation (SD) of 11 degrees to 49 with a SD of 10 degrees in 1 year. The average score of the AOFAS scale improved from 61 points (range: 35-80) to 86 points (range: 75-95). The VAS pain scale improved from 4.7 with a SD of 2.6 points to 2.5 with a SD of 1.9 points. One patient developed metatarsalgia in the second metatarsophalangeal joint and only required conservative treatment. Konkel et al. followed up 23 patients for 72 months (17 had HR grade 3, and 6 had HR grade 4). The average age was 62 years. There were two patients with mild clawing of the great toe and two of mild transfer metatarsalgia. The average plantar flexion increased from 1 degree with a range of (-15 to 15) to 13 degrees with a range of (-20 to 30$)$. For dorsiflexion, there was an average improvement from 16 ( 5 to 50 ) to 60 (20 to 85) degrees. In the score of the AOFAS scale the change was from 19 (17 to 50 ) to 89 (40 to 100) points.
At the end of the follow-up there was a $68 \%$ of recurrent dorsal osteophytes, the recurrence was mild in 10 patients, moderate in 4 , and severe in 6 , while 8 patients had no recurrence. There were three unsatisfied patients; a hard- working man in the construction industry, a woman who worked in a marketing industry and had to wear designer shoes, and another man who worked as a machinist in a factory and had to stand all day ${ }^{[22]}$.

In this paper two finite element models of the foot have been presented. The first model analyses a healthy foot and the second model analyses the same foot having released a HitFPP. We found that when the hemiarthroplasty is performed the rays 2 and 3 become overloaded. In the first model, it was also observed that thin ligaments between first metatarsal and proximal phalanx, the pedio muscle, capsularis, flexor hallucis brevis, hallux adductor, and hallux abductor muscles transmit the most loads to the first proximal phalanx in the toe-off stage; these muscles and ligaments are disconnected in the surgical procedure. When performing the arthroplasty, it was also observed that passive windlass mechanism is lost despite not having disconnected the extensor hallucis longus muscle in the surgical procedure. The FRotF gives the ability to walk on uneven terrain ${ }^{[23]}$. This capacity could be affected after having developed an HitFPP. We recommend further work to evaluate the mechanism of active windlass in patients during postsurgical follow-up. The tensile strength yield for CrCo alloy is $410 \mathrm{MPa}$ and this value is higher than the von Mises stresses reported in this paper (27.47 MPa). This indicates that failure for this implant may be due to fatigue problem ${ }^{[25]}$.

\section{CONCLUSIONS}

Some authors have reported metatarsalgia in the second toe as a side effect of the first phalangeal arthroplasty ${ }^{[21]}{ }^{[22]}$ and Garcia-Aznar et al. have shown that when the FRotF is unloaded, the others are overloaded, thus increasing the risk of metatarsalgia ${ }^{[24][17]}$. 
For the healthy model, the results have a good correlation with a similar models presented by Enrique Morales et al. ${ }^{[15]}$, Marco A. Martinez et al. ${ }^{[4]}$ and Mario Alberto Madrid et al. ${ }^{[9]}$. These are the same model with minor modifications through various researches, while for the implant model there is no experimental validation because nobody has done it before, however there are clinical results that coincide with the results obtained in the implant model ${ }^{[21][22]}$. This study makes a comparison of a foot free of any pathology with a foot that undergoes a HitFPP. It is worth to note that most people who undergo this procedure feel great relief after the postsurgical rehabilitation because, before the operation, they could not walk, jump, run, or wear shoes as normal.

The results shown in Figs. 5, 6 and 8 correspond to the condition loading of 1.0 times the person's own weight. Since the implant is made from metal, we use the von Mises stresses, while for hard and soft tissues we use the principal stresses. The distribution of stress in the three analysed loading conditions was similar. The higher value of load condition the higher values of stress and strain in the model. The values of the displacements in the lesser toes increased when the load condition increased, but for the healthy model the displacements of the distal phalanx of the great toe, because of the windlass mechanism, obtained the same value in the three load conditions. In the hemiarthroplasty model the values of the displacements in first distal phalanx are null in all load conditions. The maximum von Mises stress obtained in this study is $6.7 \%$ of the yield strength ${ }^{[25]}$, thus failure for this implant could be due to fatigue problem.
Because it is a destructive procedure, the HitFPP is usually one of the last options for patients with HR in advanced stages of the pathology. Many authors have compared this procedure with other procedures, such as Keller's arthroplasty, hemiarthroplasty of the first metatarsal or implant arthroplasty that replace the entire FMJ ${ }^{[5][6]}$.

On the other hand, the use of finite element analysis has helped to understand the changes in foot biomechanics after having been developed an HitFPP. Despite these efforts, there is still much work to be done to find an effective and efficient way to return a comfortable and painless life to people suffering from these pathologies that continue to have no cure.

\section{AUTHOR CONTRIBUTIONS}

M.A.M.P. Contributed to elaboration of models, writing the manuscript and interpretation of results.

R.B.B.V. Contributed to review the anatomy and the arthroplasty process of the models, interpretation of results, writing and reviewing the manuscript.

J.B.L. Contributed to software licenses, interpretation of results, reviewed and writing the manuscript.

\section{ACKNOWLEDGEMENTS}

The authors gratefully acknowledge the support of the Ministry of Economy and competitiveness of the Government of Spain through the project DPI201677016-R. 


\section{REFERENCES}

[1] Núñez-Samper M, Llanos Alcázar LF. Biomecánica, medicina y cirugía del pie. Barcelona: Masson, S. A; 2000.

[2] Polzer H, Polzer S, Brumann M, et al. Hallux rigidus: Joint preserving alternatives to arthrodesis - a review of the literature. World J Orthop [Internet]. 2014;5(1):6-13. Available from: https://dx.doi.org/10.5312/wjo.v5.i1.6

[3] Asunción Márquez J, Martín Oliva X. Hallux rígidus: Etiología, diagnóstico, clasificación y tratamiento. Rev Esp Cir Ortop Traumatol [Internet]. 2010;54(5):321-328. Available from: https://doi.org/10.1016/j.recot.2010.05.005

[4] Martínez Bocanegra MA, Bayod Lopez J, Vidal-Lesso A, et al. Structural interaction between bone and implants due to arthroplasty of the first metatarsophalangeal joint. Foot Ankle Surg [Internet]. 2019;25(2):150-157. Available from: https://doi.org/10.1016/j.fas.2017.10.002

[5] Delman C, Kreulen C, Sullivan M, et al. Proximal Phalanx Hemiarthroplasty for the Treatment of Advanced Hallux Rigidus. Foot Ankle Clin [Internet]. 2015;20(3):503-512. Available from: https://doi.org/10.1016/j.fcl.2015.05.002

[6] Perler AD, Nwosu V, Christie D, et al. End-Stage Osteoarthritis of the Great Toe/Hallux Rigidus. A Review of the Alternatives to Arthrodesis: Implant Versus Osteotomies and Arthroplasty Techniques. Clin Podiatr Med Surg [Internet]. 2013;30(3):351-395. Available from: https://doi.org/10.1016/j.cpm.2013.04.011

[7] Morales-Orcajo E, Bayod J, Becerro-de-Bengoa-Vallejo R, et al. Influence of first proximal phalanx geometry on hallux valgus deformity: a finite element analysis. Med Biol Eng Comput [Internet]. 2015;53:645-653. Available from: https://doi.org/10.1007/s11517-015-1260-4

[8] Kristen K-H, Berger K, Berger C, et al. The First Metatarsal Bone Under Loading Conditions : A Finite Element Analysis. Foot Ankle Clin [Internet]. 2005;10(1):1-14. Available from: https://doi.org/10.1016/j.fcl.2004.11.003

[9] Madrid MA, de Bengoa Vallejo RB, López JB. Biomechanical Evaluation of Hemiarthroplasty in First Metatarsal Bone. In: González Díaz C, et al. (eds). VIII Latin American Conference on Biomedical Engineering and XLII National Conference on Biomedical Engineering CLAIB 2019 [Internet]. Cancún: IFMBE Proceedings; 2019:831-840. Available from: https://doi.org/10.1007/978-3-030-30648-9_109

[10] Becerro de Bengoa Vallejo R, Losa Iglesias ME, Jules KT. Tendon Insertion at the Base of the Proximal Phalanx of the Hallux: Surgical Implications. J Foot Ankle Surg [Internet]. 2012;51(6):729733. Available from: https://doi.org/10.1053/j.jfas.2012.06.004

[11] Ramos AR. Estudio por elementos finitos del comportamiento del pie [dissertation]. [Zaragoza]: Universidad de Zaragoza; 2006. Spanish.

[12] Moharrami N, Langton DJ, Sayginer O, et al. Why does titanium alloy wear cobalt chrome alloy despite lower bulk hardness: A nanoindentation study? Thin Solid Films [Internet].

2013;549(31):79-86. Available from: https://doi.org/10.1016/i.tsf.2013.06.020
[13] Çelik I. Influence of CrN Coating on Electrochemical Behavior of Plasma Nitrided Pure Titanium in Bio-simulated Environment. J Bionic Eng [Internet]. 2016;13:150-155. Available from: https://doi.org/10.1016/S1672-6529(14)60169-4

[14] Tanner KE. Titanium in Medicine. Proc Inst Mech Eng H [Internet]. 2002;216(3):215-215. Available from: https://doi.org/10.1243/0954411021536432

[15] Morales Orcajo E.. Influencia de la geometría de la falange proximal en la formación de juanetes [master's thesis]. [Zaragoza]: Universidad de Zaragoza; 2012. Spanish.

[16] Bayod J, Losa-Iglesias M, Becerro de Bengoa-Vallejo R, et al. Advantages and Drawbacks of Proximal Interphalangeal Joint Fusion Versus Flexor Tendon Transfer in the Correction of Hammer and Claw Toe Deformity. A Finite-Element Study. J Biomech Eng [Internet]. 2010;132(5):51002. Available from: https://doi.org/10.1115/1.4001115

[17] Bayod J, Becerro de Bengoa Vallejo R, Losa Iglesias ME, et al. Stress at the Second Metatarsal Bone After Correction of Hammertoe and Claw Toe Deformity: A Finite Element Analysis Using an Anatomical Model. J Am Podiatr Med Assoc [Internet]. 2013;103(4):260-73. Available from: https://doi.org/10.7547/1030260

[18] García-González A, Bayod J, Prados-Frutos JC, et al. Finite-element simulation of flexor digitorum longus or flexor digitorum brevis tendon transfer for the treatment of claw toe deformity. J Biomech [Internet]. 2009;42(11):1697-1704. Available from: https://doi.org/10.1016/j.jbiomech.2009.04.031

[19] Marco Sanz C. Cinesiologia de la marcha humana normal [Internet]. Universidad de Zaragoza; 2011. Available from: $h t t p: / /$ wzar.unizar.es/acad/cinesio/MaterialDidactico.html

[20] DeHeer PA. The Case Against First Metatarsal Phalangeal Joint Implant Arthroplasty. Clin Podiatr Med Surg [Internet]. 2006;23(4):709-723. Available from: https://doi.org/10.1016/j.cpm.2006.08.001

[21] Giza E, Sullivan M, Ocel D, et al. First metatarsophalangeal hemiarthroplasty for hallux rigidus. Int Orthop [Internet]. 2010;34:1193-1198. Available from: https://doi.org/10.1007/s00264-010-1012-x

[22] Konkel KF, Menger AG, Retzlaff SA. Results of Metallic Hemi-Great Toe Implant for Grade III and Early Grade IV Hallux Rigidus. Foot Ankle Int [Internet]. 2009;30(7):653-660. Available from: https://doi.org/10.3113/FAl.2009.0653

[23] Kirby K. Foot and lower extremity biomechanics, Vol. IV. Payson: Precision Intricast Newsletter ;1997. 142p.

[24] García-Aznar JM. Bayod J, Rosas A, et al. Load Transfer Mechanism for Different Metatarsal Geometries: A Finite Element Study. J Biomech Eng [Internet]. 2008;131(2):021011. Available from: https://doi.org/10.1115/1.3005174

[25] Dolgov, N A, Dikova T, Dzhendov D, et al. Mechanical Properties of Dental Co-Cr Alloys Fabricated via Casting and Selective Laser Melting. Int Sci J Materials Science. Non-Equilibrium Phase Transformation. 2016;2(3):29-33. 